\title{
Comparison of novel and established caries diagnostic methods: a clinical study on occlusal surfaces
}

Friederike Litzenburger*, Gerrit Schäfer, Reinhard Hickel, Jan Kühnisch and Katrin Heck

\begin{abstract}
Background: The purpose of this prospective clinical diagnostic study with validation was to compare the diagnostic accuracy of near-infrared transillumination (NIRT), laser fluorescence measurement (LF), alternating current impedance spectroscopy (ACIS) and their combinations as adjunct methods to visual examination (VE) for occlusal caries detection using a hybrid reference standard.

Methods: Ninety-six first and second non-cavitated permanent molars from 76 individuals (mean age 24.2) were investigated using (VE) (ICDAS) and bitewing radiography (BWR), as well as NIRT, LF and ACIS. The findings of BWR and NIRT were evaluated by two examiners while the other examinations were conducted by one calibrated dentist. The hybrid reference standard consisted of non-operative validation based on the results of VE and BWR and operative validation. Statistical analysis included cross-tabulations, calculation of sensitivity, specificity and area under the receiver operating characteristic curve at three diagnostic thresholds: caries in general, enamel caries and dentin caries.
\end{abstract}

Results: NIRT, LF and ACIS exhibited high sensitivity for caries in general [1.00 (1.00-1.00), 0.77 (0.65-0.88), 0.75 (0.63$0.87))$ and for dentin caries $(0.97(0.91-1.03), 0.76(0.76-0.90), 0.64(0.47-0.80)]$. Sensitivity values for enamel caries were weak $(0.21,0.11,0.37)$. Specificity values did not fall below 0.65 (NIRT) for all categories and methods, except for NIRT at the caries detection threshold (0.27). A combination of LF and ACIS with VE improved the diagnostic performance at the overall and the enamel caries threshold. The other methods showed fair to excellent discrimination at the overall caries threshold (NIRT 0.64, LF 0.89 and ACIS 0.86) and acceptable discrimination at the dentin caries threshold (NIRT 0.82, LF 0.81 and ACIS 0.79). AUROC for enamel caries exhibited the weakest discrimination. Accuracy was $65.6 \%$ for VE, $69.8 \%$ for BWR, 50.0\% for NIRT, 53.1\% for LF and 74.0\% for ACIS. Reliability assessment for BWR and NIRT showed at least substantial agreements for all analyses.

Conclusions: The methods, NIRT, LF and ACIS, revealed different potential but no impeccable performance for occlusal caries detection. All are suitable instruments to detect hidden carious lesion in dentin. As auxiliaries to VE, LF and ACIS showed an increase in diagnostic performance.

Keywords: Dental caries, Occlusal caries, Occlusal caries detection, Diagnostic imaging, Near-infrared transillumination, Bitewing radiography, Laser-fluorescence, Alternating current impedance spectroscopy, Sensitivity, Specificity

*Correspondence: soechtig@dent.med.uni-muenchen.de

Department of Conservative Dentistry and Periodontology, University

Hospital, Ludwig-Maximilians-University of Munich, Munich, Germany

\section{Background}

Dental caries is still a prevalent disease [1]. However, in industrialized countries, the prevalence of caries has declined, and lesion appearance has shifted towards a

(c) The Author(s) 2021. Open Access This article is licensed under a Creative Commons Attribution 4.0 International License, which permits use, sharing, adaptation, distribution and reproduction in any medium or format, as long as you give appropriate credit to the original author(s) and the source, provide a link to the Creative Commons licence, and indicate if changes were made. The images or other third party material in this article are included in the article's Creative Commons licence, unless indicated otherwise in a credit line to the material. If material is not included in the article's Creative Commons licence and your intended use is not permitted by statutory regulation or exceeds the permitted use, you will need to obtain permission directly from the copyright holder. To view a copy of this licence, visit http://creativecommons.org/licenses/by/4.0/. The Creative Commons Public Domain Dedication waiver (http://creativeco mmons.org/publicdomain/zero/1.0/) applies to the data made available in this article, unless otherwise stated in a credit line to the data. 
larger portion of non-cavitated caries [2-6]. Optimal caries management requires structured caries detection, assessment, and diagnostic procedures. Visual examination (VE) is recognized as the first method of choice due to its simplicity, acceptable validity and reliability, especially for early occlusal caries detection and assessment $[3,7,8]$. Besides, bitewing radiography (BWR) is frequently considered adjunct diagnostic method of choice because of its widespread availability in dental practices, complete imaging of the posterior region on one side of the jaw, visualization of caries extension in relation to the pulp and acceptable validity and reliability [9]. Aiming at limiting the exposure to ionizing radiation for dental diagnostic purposes, many X-ray-free diagnostic methods have been introduced on the dental market. Here, laser fluorescence measurement (LF), e.g. the DIAGNOdent (KaVo, Biberach, Germany), was first proven to be a valuable method for the evaluation of occlusal sites [10]. Since then, several other-mostly light-opticaldevices have been developed and have received increasing clinical and scientific attention. Near-infrared light transillumination (NIRT) and alternating current impedance measurement (ACIS) have been recently introduced into dental practice [11-13], and only a few diagnostic studies have analysed their diagnostic performance for occlusal caries detection thus far [14-20]. A few clinical studies directly compared the diagnostic performances of these adjunct methods, highlighting their individual potential for occlusal caries detection at the enamel and dentin threshold [15, 21, 22].

The objective of this clinical study using a hybrid reference standard was to compare the diagnostic accuracy of NIRT, LF and ACIS alone and as adjunct methods to VE for occlusal caries detection in relation to the thresholds for overall caries, enamel caries and dentin caries. The null hypothesis was that all diagnostic procedures would exhibit similar diagnostic performance.

\section{Methods}

This prospectively designed clinical diagnostic study was approved by the Ethics Committee of the Medical Faculty of the Ludwig-Maximilians University of Munich (Project Number 013-12).

\section{Sample size calculation}

The assumed caries prevalence of the study population is approximately $50 \%$. Aiming for a power of $80 \%$ and setting alpha to 0.05 with the null hypothesis for sensitivity (SE) and specificity (SP) at 0.5 , which was supposed to increase to $0.7,98$ samples were calculated to be required [23].

\section{Eligibility of patients and teeth}

The participants of this study were patients who came to the Department of Conservative Dentistry in Munich with the request for a dental examination and/or treatment from December 2012 to July 2014. Only healthy patients in generally good condition (ASA 1), with a minimum age of 12 years and a fully erupted permanent dentition were included. Further inclusion criteria were the presence of at least one molar without restoration, fissure sealing, orthodontic treatment, development defects or macroscopic cavitations. If these inclusion criteria were met, the patient was explained the study design and asked to participate (JK and FL). In case of a positive response, written informed consent was obtained. A further prerequisite for participation was the availability of bitewing radiographs which were not older than four months. New radiographs were only prescribed when there was a justifiable indication. These radiographs were analysed by the recruiting dentists (JK and FL) as part of the initial examination. The patients were informed about their findings, and all adequate therapeutic options were enumerated and offered.

\section{Clinical examination}

Visual examination was performed using magnifying lights (magnification: $2.5 \times$, focal distance: $300-550 \mathrm{~mm}$, field of view: $67-115 \mathrm{~mm}$ ) after a professional tooth cleaning after $\sim 5 \mathrm{~s}$ of air-drying by two calibrated dentists (JK and FL). All results of the VE were discussed and evaluated among the examiners (JK and $\mathrm{FL}$ ) during the same appointment. The findings were categorized according to the International Caries Detection and Assessment System II (ICDAS) for occlusal surfaces with the following relevant scores: sound, first visible change in enamel, distinct visible change in enamel and localized enamel breakdown without visible dentin or underlying shadow [7]. Photographs were captured to allow later reassessment of the surfaces.

\section{Digital bitewing radiography}

Bitewing radiographs were acquired using an intraoral dental X-ray machine with a $203 \mathrm{~mm}$ tube (Heliodent DS, Sirona, Bensheim, Germany) including an X-ray field limitation $(30 \times 40 \mathrm{~mm})$ with a CCD sensor (Intraoral II, sensor size $30.7 \times 40.7 \mathrm{~mm}$, Sirona, Bensheim, Germany) and an exposure time of $0.06 \mathrm{~s}$ at a cathode voltage of $60 \mathrm{kV}$ and $7 \mathrm{~mA}$ of amperage. For the parallel technique, a sensor-holding system (XPP-DS Digital Sensor Holders for Sirona, Dentsply Rinn, Elgin, IL, USA) was used. Evaluation of all radiographs was conducted by two examiners (FL and $\mathrm{KH}$ ) independently from each other and blindly from other diagnostic findings in a darkened 


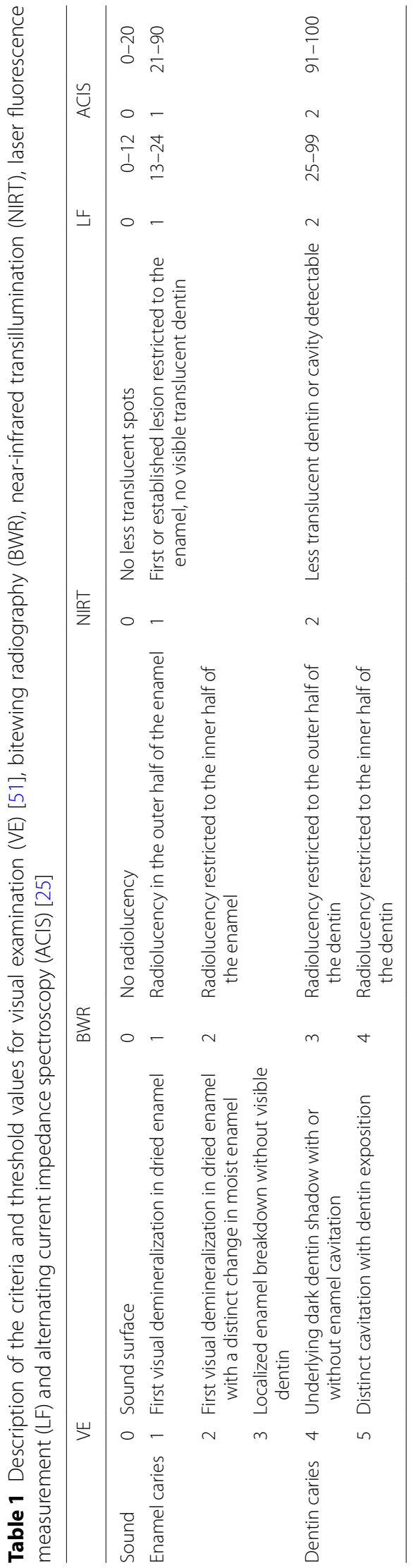


room on a standard calibrated monitor according to the following criteria: no signs of various decalcification, translucence in enamel or translucence in dentin (Table 1). If the examiners made different diagnoses, then they re-assessed the corresponding radiographs, discussed their findings, and reached a consensus finding.

\section{Near-infrared light transillumination}

NIRT was conducted with a Diagnocam camera system (KaVo, Biberach, Germany) on dried occlusal surfaces. The light source of the dental unit was switched off, and the images from the corresponding occlusal surfaces were captured with the KID software (KaVo Integrated Desktop/version 2.4.1.6374, KaVo, Biberach, Germany) installed on a laptop. Analysis of the images was performed twice by two experienced dentists (FL and $\mathrm{KH}$ ) according to the following criteria: no less translucent spots, caries visible limited to the enamel and no less translucent dentin, less translucent dentin or cavity visible [24]. Divergent results were discussed until a consensus finding was reached.

\section{Laser fluorescence measurements}

LF was performed using a DIAGNOdent Pen device (KaVo, Biberach, Germany). The device was regularly calibrated according to the manufacturer's instructions. Furthermore, the rounded glass tip of the device was individually adjusted to the autofluorescence of the tooth at a healthy dental area after brief air drying. Measurements of the occlusal surface were then made. The maximum LF reading (0-99) was recorded, and the measurements were defined as follows: 0-12 sound, 13-24 enamel and 24-99 dentin involvement [25].

\section{Alternating current impedance spectroscopy}

ACIS was conducted with the CarieScan Pro device (orange dental, Biberach, Germany) on air-dried molar teeth and fissures isolated with cotton rolls. The ACIS readings were defined according to the following thresholds: 0-20 sound, 21-90 demineralized enamel and 91-100 dentin involvement [25].

\section{Treatment decision, validation and definition of the reference standard}

After the clinical assessment using the different diagnostic methods as described above, a management strategy was determined for all 96 molar teeth. This management included surface-related factors, e.g., the extent of caries in relation to the pulp, presence of (micro-) cavitation and caries activity as well as the overall caries risk of each subject [5]. All steps were pre-discussed in the study group and finally agreed to by each patient. To make the independent reference standard more powerful, VE and
BWR were evaluated by three different examiners (JK, FL and $\mathrm{KH}$ ) as described above.

The hybrid reference standard consisted of two different procedures in relation to the diagnostic findings to meet the ethical requirement of an in vivo analysis. The samples undergoing non-operative validation were evaluated as healthy or occlusal surfaces with a noncavitated carious lesion according to the findings of $\mathrm{VE}$ and BWR, which did not justify any restorative intervention $(\mathrm{N}=56)$. The lesions without the need for operative care were integrated into an individual prophylaxis and monitoring concept. The other group, undergoing operative intervention, consisted of samples that exhibited the indication for restorative care, which was conducted at a separate appointment a maximum of two weeks after diagnosis $(\mathrm{N}=40)$. For operative validation, carious dentin was removed using restrictive and selective caries removal techniques [26]. Soft dentin beneath the pulp was excavated with a self-limiting polymer bur (P1, Komet, Lemgo, Germany). The assignment at the reference values was conducted immediately after caries excavation according to the listed scores in Table 1 by one examiner (FL). After excavation and clinical judgement, the cavity was photographed for later independent reassessment. Finally, the cavity was restored with an adhesively bonded restoration (Syntac classic, Vivadent, Schaan, Lichtenstein; SONICfill, KaVo, Biberach, Germany; SonicFILL, West Collins, Orange, CA, USA). All patients were consistently informed about appropriate home-based preventive measures and were offered riskrelated professional preventive dental care aiming at lowering caries activity and risk. All treatment decisions were made in cooperation with all examiners (JK, FL and $\mathrm{KH})$ throughout the study period.

\section{Training and calibration of all diagnostic methods and the validation process}

The examiners ( $\mathrm{FL}$ and $\mathrm{KH}$ ) underwent two-day theoretical and practical training for all diagnostic procedures used in this study (VE, BWR, NIRT, LF and ACIS) under the guidance of an experienced dentist (JK). The training included information pertaining to the study design, indices, diagnostic principles of all methods and validation procedure. The examiners then evaluated a new set of bitewing radiographs and NIRT images in the trainer's presence while discordant findings were immediately discussed, and a consensus diagnosis was reached. Subsequently, the reliability between and within the examiners $(\mathrm{FL}$ and $\mathrm{KH})$ was determined based on 50 case examples of BWR and NIRT, and an inter-/and intra-examiner agreement of more than 90\% was achieved (linear weighted kappa analysis). The training was completed by a clinical 
training course, during which the examiner (FL) performed clinical examinations using all diagnostic methods (VE, BWR, NIRT, LF, and ACIS) and validated ten carious dentin lesions according to the study protocol under supervision (JK).

\section{Statistical analysis}

After data entry using a spreadsheet (Microsoft Excel, Version 16.36), statistical analysis was conducted using the statistical software SPSS (IBM SPSS Statistics for Windows, Version 25.0, Armonk, NY, USA) and R [27]. Diagnostic results from the test methods or their combinations with VE were cross-classified with the findings from the hybrid reference standard using the predefined definitions in Table 1. Overall accuracy was calculated as the percentage of correctly classified decisions $(\mathrm{TP}+\mathrm{TN}) /(\mathrm{TP}+\mathrm{TN}+\mathrm{FP}+\mathrm{FN})$, where $\mathrm{TP}, \mathrm{FN}$, FP and TN represent the counts of true positives, false negatives, false positives and true negatives, respectively. In addition to descriptive data analysis, contingency tables for cross-classification and calculation of SE and SP were done [28]. These procedures were consistently performed for all test methods and their combination using three diagnostic thresholds. These threshold values were, as shown in Table 1, enamel caries and dentin caries but also overall caries, which includes dentin caries and enamel caries together. Furthermore, the area under the receiver operating characteristic (AUROC) was calculated, and multiple comparisons between the AUROC from different methods and thresholds were conducted [29]. To interpret the AUROC, the classification by Hosmer and Lemeshow [30] was applied: AUROC value $0.5-0.7=$ poor to fair discrimination; AUROC value of $0.7-0.8=$ acceptable discrimination; AUROC value of $0.8-0.9=$ excellent discrimination and $\mathrm{AUC} \geq 0.9=$ outstanding discrimination. If the area under the AUROC was 0.50, the model did not discriminate. The inter-/and intraexaminer reliability values were calculated using linear weighted Cohen's kappa, where a 1-category difference could be considered as less severe than a 2-category difference. Weights ranged from 0 to 1 , and the weight for cells where the raters disagreed exactly equalled 1 . For cells in the lower left or upper right corners with the largest disagreement, the weight equalled 0. Each weight (W) for any cell was calculated by the formula $\mathrm{Wxy}=1-(|\mathrm{x}-\mathrm{y}|) / \mathrm{z}$, with $\mathrm{x}$ and $\mathrm{y}$ being the categories and $\mathrm{z}$ the total number of categories. Kappa values were categorized as poor $(<0.00)$, slight $(0.00-0.20)$, fair (0.21-0.40), moderate (0.41-0.60), substantial $(0.61-0.80)$, and almost perfect agreement $(0.81-1.00)$ [31-33].

\section{Results}

Out of 155 patients evaluated for eligibility, 76 participants with 96 occlusal surfaces met the inclusion criteria (Fig. 1). A maximum of two teeth per patient were randomly selected for statistical analysis. The median age of the study participants was 24.2 years (range 14-49, 6 adolescents and 70 adults, 45 women and $31 \mathrm{men}$ ), and their caries prevalence was moderate according to WHO criteria (5.9 DMFT and 11.2 DMFS). A total of $45.8 \%(\mathrm{~N}=44)$ of the relevant occlusal surfaces were found to be caries-free, $19.8 \%(\mathrm{~N}=19)$ were restricted to the enamel and $34.4 \%(\mathrm{~N}=33)$ reached the dentin according to the hybrid reference standard (Table 2). Cross-classifications for findings of each diagnostic test method and its combination with VE in relation to the hybrid reference standard can be taken from Table 2. Overall accuracy for the two reference methods were $65.6 \%$ for VE and $69.8 \%$ for BWR. For the test methods, overall accuracy were $50.0 \%$ for NIRT, $53.1 \%$ for LF and $74.0 \%$ for ACIS. Outcome measures for diagnostic performance are summarized in Table 3 and the highest values in terms of SE and SP are highlighted in relation to the threshold used. The main results in terms of the diagnostic performance are as follows: LF and ACIS exhibited high SE for caries in general $(0.77 / 0.75)$ and moderate for dentin caries $(0.76 / 0.64)$,

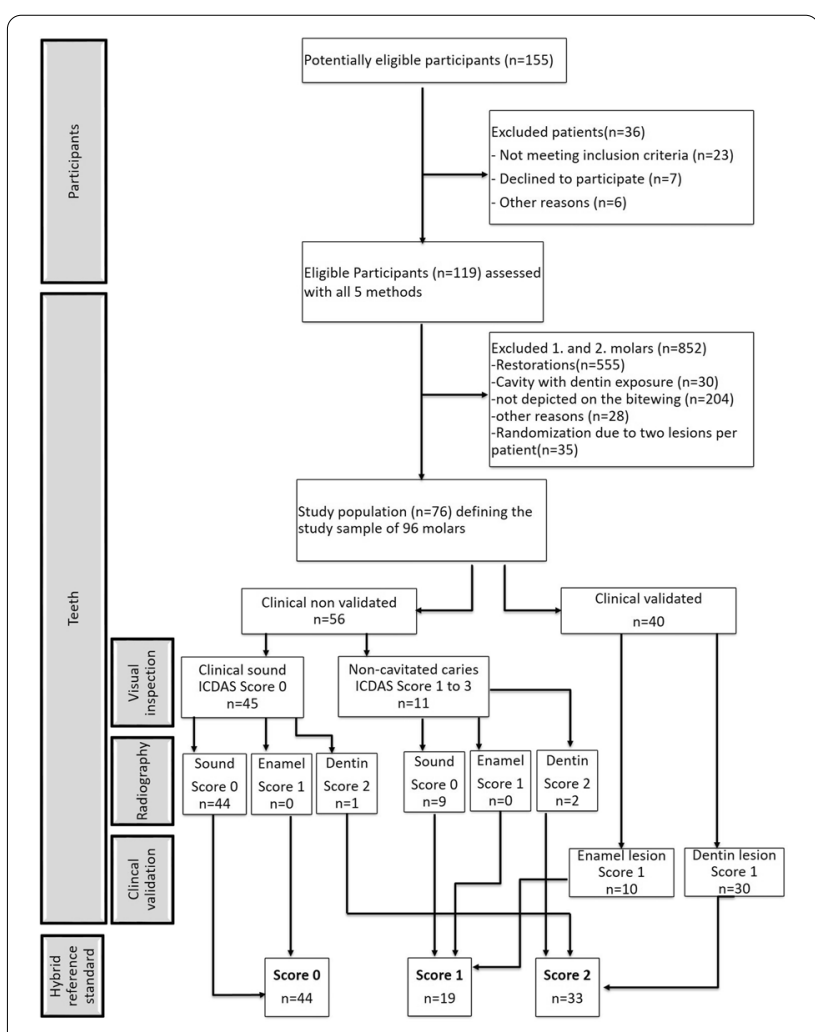

Fig. 1 Flow diagram through the process of this diagnostic study 
Table 2 Cross-table for comparison of all findings of visual examination (VE), bitewing radiography (BWR), laser fluorescence measurement (LF), near-infrared transillumination (NIRT) and alternating current impedance spectroscopy (ACIS) at three diagnostic thresholds

\begin{tabular}{|c|c|c|c|c|c|}
\hline & & \multicolumn{4}{|c|}{ Reference standard } \\
\hline & & No caries & $\begin{array}{l}\text { Enamel } \\
\text { caries }\end{array}$ & Dentin caries & Total \\
\hline \multicolumn{6}{|c|}{ Diagnostic test method } \\
\hline \multirow[t]{3}{*}{ VE } & No caries & 44 & 0 & 3 & 47 \\
\hline & $\begin{array}{r}\text { Enamel } \\
\text { caries }\end{array}$ & 0 & 19 & 30 & 49 \\
\hline & Dentin caries & 0 & 0 & 0 & 0 \\
\hline \multirow[t]{3}{*}{ BWR } & No caries & 44 & 19 & 10 & 73 \\
\hline & $\begin{array}{r}\text { Enamel } \\
\text { caries }\end{array}$ & 0 & 0 & 0 & 0 \\
\hline & Dentin caries & 0 & 0 & 23 & 23 \\
\hline \multirow[t]{3}{*}{ NIRT } & No caries & 12 & 0 & 0 & 12 \\
\hline & $\begin{array}{r}\text { Enamel } \\
\text { caries }\end{array}$ & 26 & 4 & 1 & 31 \\
\hline & Dentin caries & 6 & 15 & 32 & 53 \\
\hline \multirow[t]{3}{*}{ LF } & No caries & 44 & 8 & 4 & 56 \\
\hline & $\begin{array}{r}\text { Enamel } \\
\text { caries }\end{array}$ & 0 & 2 & 4 & 6 \\
\hline & Dentin caries & 0 & 9 & 25 & 34 \\
\hline \multirow[t]{3}{*}{$\mathrm{ACIS}$} & No caries & 43 & 9 & 4 & 56 \\
\hline & $\begin{array}{r}\text { Enamel } \\
\text { caries }\end{array}$ & 1 & 7 & 8 & 16 \\
\hline & Dentin caries & 0 & 3 & 21 & 24 \\
\hline \multirow[t]{3}{*}{ VE/BWR } & No caries & 44 & 0 & 0 & 44 \\
\hline & $\begin{array}{r}\text { Enamel } \\
\text { caries }\end{array}$ & 0 & 19 & 10 & 29 \\
\hline & Dentin caries & 0 & 0 & 23 & 23 \\
\hline \multirow[t]{3}{*}{ VE/NIRT } & No caries & 12 & 0 & 0 & 12 \\
\hline & $\begin{array}{r}\text { Enamel } \\
\text { caries }\end{array}$ & 26 & 4 & 1 & 31 \\
\hline & Dentin caries & 6 & 15 & 32 & 53 \\
\hline \multirow[t]{3}{*}{ VE/LF } & No caries & 44 & 0 & 2 & 46 \\
\hline & $\begin{array}{r}\text { Enamel } \\
\text { caries }\end{array}$ & 0 & 10 & 6 & 16 \\
\hline & Dentin caries & 0 & 9 & 25 & 34 \\
\hline \multirow[t]{3}{*}{ VE/ACIS } & No caries & 43 & 0 & 1 & 44 \\
\hline & $\begin{array}{r}\text { Enamel } \\
\text { caries }\end{array}$ & 1 & 16 & 11 & 28 \\
\hline & Dentin caries & 0 & 3 & 21 & 24 \\
\hline Total & & 44 & 19 & 33 & 96 \\
\hline
\end{tabular}

while SE for enamel caries was low $(0.11 / 0.37)$. Both methods demonstrate high values of SP at all three diagnostic thresholds. NIRT showed lower values of SP at the overall caries and the dentin caries threshold $(0.27 / 0.67)$ but associated with excellent SE values (1.00/0.97). For enamel caries NIRT exhibited low SE (0.21) accompanied
Table 3 Values for sensitivity (SE), specificity (SP) and the area under the receiver operating characteristics (AUROC) for visual examination (VE), bitewing radiography (BWR), laser fluorescence measurement (LF), near-infrared transillumination (NIRT) and alternating current impedance spectroscopy (ACIS) with and without visual examination (VE) are calculated at three diagnostic thresholds

\begin{tabular}{|c|c|c|c|}
\hline Method & SE & $\mathrm{SP}$ & AUROC \\
\hline \multicolumn{4}{|c|}{ Caries detection } \\
\hline VE & $0.94(0.88-1.01)$ & $1.00(1.00-1.00)$ & $0.97(0.93-1.00)$ \\
\hline BWR & $0.44(0.31-0.58)$ & $1.00(1.00-1.00)$ & $0.72(0.62-0.82)$ \\
\hline NIRT & $1.00(1.00-1.00)$ & $0.27(0.14-0.40)$ & $0.64(0.52-0.75)$ \\
\hline LF & $0.77(0.65-0.88)$ & $1.00(1.00-1.00)$ & $0.89(0.81-0.96)$ \\
\hline ACIS & $0.75(0.63-0.87)$ & $0.98(0.93-1.02)$ & $0.86(0.79-0.94)$ \\
\hline VE/BWR & $1.00(1.00-1.00)$ & $1.00(1.00-1.00)$ & $1.00(1.00-1.00)$ \\
\hline VE/NIRT & $1.00(1.00-1.00)$ & $0.27(0.14-0.40)$ & $0.64(0.52-0.75)$ \\
\hline VE/LF & $0.96(0.91-1.01)$ & $1.00(1.00-1.00)$ & $0.98(0.95-1.00)$ \\
\hline VE/ACIS & $0.98(0.94-1.02)$ & $0.98(0.93-1.02)$ & $0.98(0.95-1.00)$ \\
\hline \multicolumn{4}{|c|}{ Enamel caries detection } \\
\hline VE & $1.00(1.00-1.00)$ & $0.61(0.50-0.72)$ & $0.81(0.72-0.89)$ \\
\hline BWR & $0.00(0.00-0.00)$ & $1.00(1.00-1.00)$ & $0.50(0.35-0.65)$ \\
\hline NIRT & $0.21(0.03-0.39)$ & $0.65(0.54-0.76)$ & $0.43(0.29-0.57)$ \\
\hline LF & $0.11(-0.03$ to 0.24$)$ & $0.95(0.90-1.00)$ & $0.53(0.38-0.68)$ \\
\hline ACIS & $0.37(0.15-0.59)$ & $0.88(0.81-0.95)$ & $0.63(0.47-0.78)$ \\
\hline VE/BWR & $1.00(1.00-1.00)$ & $0.87(0.80-0.95)$ & $0.94(0.89-0.98)$ \\
\hline VE/NIRT & $0.21(0.03-0.39)$ & $0.65(0.54-0.76)$ & $0.43(0.29-0.57)$ \\
\hline VE/LF & $0.53(0.30-0.75)$ & $0.92(0.86-0.98)$ & $0.72(0.58-0.87)$ \\
\hline VE/ACIS & $0.84(0.68-1.01)$ & $0.84(0.76-0.93)$ & $0.84(0.74-0.95)$ \\
\hline \multicolumn{4}{|c|}{ Dentin caries detection } \\
\hline VE & $0.00(0.00-0.00)$ & $1.00(1.00-1.00)$ & $0.50(0.38-0.62)$ \\
\hline BWR & $0.70(0.54-0.85)$ & $1.00(1.00-1.00)$ & $0.85(0.75-0.95)$ \\
\hline NIRT & $0.97(0.91-1.03)$ & $0.67(0.55-0.78)$ & $0.82(0.73-0.90)$ \\
\hline LF & $0.76(0.61-0.90)$ & $0.86(0.77-0.94)$ & $0.81(0.71-0.91)$ \\
\hline ACIS & $0.64(0.47-0.80)$ & $0.95(0.90-1.00)$ & $0.79(0.69-0.90)$ \\
\hline VE/BWR & $0.70(0.54-0.85)$ & $1.00(1.00-1.00)$ & $0.85(0.75-0.95)$ \\
\hline VE/NIRT & $0.97(0.91-1.03)$ & $0.67(0.55-0.78)$ & $0.82(0.73-0.90)$ \\
\hline VE/LF & $0.76(0.61-0.90)$ & $0.86(0.77-0.94)$ & $0.81(0.71-0.91)$ \\
\hline VE/ACIS & $0.64(0.47-0.80)$ & $0.95(0.90-1.00)$ & $0.79(0.69-0.90)$ \\
\hline
\end{tabular}

Values greater than 0.90 are marked in bold, and values greater than 0.80 are marked in italics

by moderate SP (0.65). The best diagnostic performance of enamel caries detection was achieved by ACIS (SE $0.84 /$ SP 0.84 ) followed by LF (SE 0.53/SP 0.92), both as adjunct methods to VE.

All methods-NIRT, LF and ACIS-consistently showed an AUROC above 0.79 for dentin caries detection (Table 3). Comparing the AUROCs within the dentin threshold, all methods discriminated equally acceptable to excellent (0.79-0.82). In contrast, NIRT did not discriminate for the enamel threshold $(0.43)$ and LF and ACIS discriminated poor to fair $(0.53 / 0.63)$. An 
improvement towards acceptable discrimination could be found for the combination of LF and ACIS with VE $(0.72 / 0.84)$, but not for the combination of NIRT with VE (0.43) (Table 3). Comparing the ROC curves within the enamel threshold, NIRT discriminated significantly poorer than all other methods $(p<0.005)$, especially if they were combined with VE (Table 4). For the overall caries threshold, NIRT and NIRT combined with VE also showed the weakest discrimination (0.64). Inter-examiner reliability was almost perfect for BWR with 0.89 (CI $0.79-1.00)$ at the first and $0.88(\mathrm{CI} 0.77-0.98)$ at the second evaluation cycle as well as for NIRT with 0.84 (CI $0.75-0.93)$ at first and 0.94 (CI $0.89-1.00)$ at the second evaluation cycle. Intra-examiner reliability was substantial to almost perfect by both examiners and methods with 0.93 (CI 0.85-1.01) and 0.92 (CI 0.84-1.01) for BWR and 0.75 (CI 0.64-0.85) and 0.84 (CI 0.75-0.93) for NIRT.

\section{Discussion}

The main objective of this in vivo diagnostic study with validation was to compare different diagnostic methods for occlusal caries detection and diagnostics at different diagnostic thresholds. It was initially hypothesized that all methods would reveal similar diagnostic performance. According to the results (Tables 2, 3, 4), the initially formulated null hypothesis must be rejected because the test methods showed heterogeneous diagnostic performance. To our knowledge, no other clinical trial has combined the comparison of the diagnostic performance of these three test methods, NIRT, LF and

Table 4 Multiple comparisons between the AUC values of visual examination (VE), bitewing radiography (BWR), nearinfrared transillumination (NIRT), laser fluorescence measurement (LF) and alternating current impedance spectroscopy (ACIS) with and without visual examination (VE) are calculated at three diagnostic thresholds

\begin{tabular}{|c|c|c|c|c|c|c|c|c|c|}
\hline AUROC difference & VE & BWR & NIRT & LF & ACIS & VE/BWR & VE/NIRT & VE/LF & VE/ACIS \\
\hline \multicolumn{10}{|c|}{ Caries detection threshold } \\
\hline VE & - & 0.25 & 0.34 & 0.09 & 0.11 & 0.03 & 0.34 & 0.00 & 0.01 \\
\hline BWR & & - & 0.09 & 0.16 & 0.13 & 0.28 & 0.09 & 0.26 & 0.26 \\
\hline NIRT & & & - & 0.25 & 0.23 & 0.36 & 0.00 & 0.34 & 0.34 \\
\hline LF & & & & - & 0.02 & 0.12 & 0.25 & 0.10 & 0.09 \\
\hline ACIS & & & & & - & 0.14 & 0.23 & 0.12 & 0.12 \\
\hline VE/BWR & & & & & & - & 0.36 & 0.02 & 0.02 \\
\hline VE/NIRT & & & & & & & - & 0.34 & 0.34 \\
\hline VE/LF & & & & & & & & - & 0.00 \\
\hline VE/ACIS & & & & & & & & & - \\
\hline \multicolumn{10}{|c|}{ Enamel caries detection threshold } \\
\hline VE & - & 0.31 & 0.38 & 0.28 & 0.18 & 0.13 & 0.38 & 0.08 & 0.04 \\
\hline BWR & & - & 0.07 & 0.03 & 0.13 & 0.44 & 0.07 & 0.22 & 0.34 \\
\hline NIRT & & & - & 0.10 & 0.20 & 0.51 & 0.00 & 0.29 & 0.41 \\
\hline LF & & & & - & 0.10 & 0.41 & 0.10 & 0.20 & 0.32 \\
\hline ACIS & & & & & - & 0.31 & 0.20 & 0.10 & 0.22 \\
\hline VE/BWR & & & & & & - & 0.51 & 0.21 & 0.09 \\
\hline VE/NIRT & & & & & & & - & 0.29 & 0.41 \\
\hline VE/LF & & & & & & & & - & 0.12 \\
\hline VE/ACIS & & & & & & & & & - \\
\hline \multicolumn{10}{|c|}{ Dentin caries detection threshold } \\
\hline VE & - & 0.35 & 0.32 & 0.31 & 0.29 & 0.35 & 0.32 & 0.31 & 0.29 \\
\hline BWR & & - & 0.03 & 0.04 & 0.05 & 0.03 & 0.03 & 0.04 & 0.05 \\
\hline NIRT & & & - & 0.01 & 0.02 & 0.00 & 0.00 & 0.01 & 0.02 \\
\hline LF & & & & - & 0.01 & 0.04 & 0.01 & 0.00 & 0.01 \\
\hline ACIS & & & & & - & 0.05 & 0.02 & 0.01 & 0.00 \\
\hline VE/BWR & & & & & & - & 0.03 & 0.04 & 0.05 \\
\hline VE/NIRT & & & & & & & - & 0.01 & 0.02 \\
\hline VE/LF & & & & & & & & - & 0.01 \\
\hline VE/ACIS & & & & & & & & & - \\
\hline
\end{tabular}


ACIS, at different diagnostic thresholds in one clinical analysis. The strength of this study is that permanent first and second molars were analysed in a predominately homogenous group of young adult or adolescent patients and that all test methods were applied under standardized clinical conditions.

The participants were evaluated and screened for study eligibility by the authors (JK and FL) before study entry. The study population included adolescents and young adults with complete permanent dentition and at least one molar without restoration, but only a sub-selection of these patients and their molars were finally included for statistical analysis. It must be reasoned that the included participants and their teeth may not be a representative sample of the targeted population and the generalisability of the study results must be regarded in this context. It can also be argued that the assumption of a caries prevalence, which is the basis of this study, is not representative for the targeted population. The following arguments justify our assumption of a $50 \%$ caries prevalence. Epidemiological data for the caries prevalence in Germany are merely available but based on oral health studies caries prevalence in 12 -year-olds is $25.2 \%$ and in $35-45$-year-olds is $97.5 \%$ [34]. Epidemiological surveys are usually based on clinical examinations of the teeth, which evaluate lesions from an advanced, clearly visible stadium while non-cavitated and/or initial lesions, as relevant in our study, mostly remain underestimated [11]. It is therefore a representative scenario for the targeted population of young adults to assume a caries prevalence of unrestored or sealed occlusal surfaces of molars with an ICDAS score of $>1$ of $50 \%$ [35-37].

Further, the study data have a clustered nature because in $26 \%$ of all cases two samples per participant were included in the evaluation. Since the structure of the enamel and dentin tissue of each subject is individual, this can influence the optical properties of the teeth and thus, this may have an impact on the results. If we had opted for only one tooth per subject, the samples size would have been reduced to 76 , which in turn would have lowered the statistical significance of this analysis. Future studies should include a complete cluster analysis.

Considering the cross-tabulation at the dentin caries threshold, the high rate of false-negative findings for VE becomes apparent (Table 2). Previous studies confirmed these findings with weak values for SE and strong values for SP for the detection of non-cavitated dentin lesions $[38,39]$. In this study, dentin lesions were not identified visually as such, because the lesions were non cavitated and predominately hidden. This explains the relatively weak values for accuracy of $65 \%$ for visual inspection in this study. This distribution of diagnostic potential is complemented by BWR, which has its strength especially in the detection of hidden dentin lesions. By excluding cavitated lesions (ICDAS Score > 3) from the study population, we were able to better demonstrate the strength of the auxiliary test methods to detect non-cavitated dentin caries. On the other hand, the analysis incorporates an incomplete caries spectrum in the sample. This limits the generalisability of the present study, as additional thresholds, e.g., other dentin caries levels, are not proved [40-42].

The type of reference standard used in this investigation provides a solution strategy for a common and wellknown problem in clinical diagnostic studies. The use of an independent and rigorous reference standard [43], e.g., histology, microradiography or $\mu \mathrm{CT}$, is not feasible in clinical investigations as it excludes sound surfaces, non-cavitated lesions or those caries stages that can be managed by non-operative measures-shortly all lesions without the indication for operative care. With the aim of overcoming this methodological disadvantage, a hybrid reference standard was used in the present study. Although this model of a reference test meets the ethical and clinical requirements, it bears the risk of sample bias. It includes information from the test methods, which contradicts the principle of independence of index and reference tests, and therefore the present study is not free of any incorporation bias. The information about the diagnostic performance of VE as an index test is limited. The focus must be on the true index tests without intersection with the reference standard, NIRT, LF and ACIS. Nevertheless, other groups have also constructed a reference standard by including results from the index tests [44-46]. The reference standard for those samples that did not undergo operative validation is formed by $\mathrm{VE}$ and BWR, while the reference standard for all samples that required operative intervention is drawn from the results of the validation process. This model of a hybrid reference standard increases the risk of differential verification bias, as not all samples are subjected to the same reference standard.

Most of the results of this clinical study are in line with previous diagnostic studies concerning the methods VE, BWR and LF [16, 47-49]. We chose magnification 2.5X to achieve optimal results of visual inspection in this study. It must be considered that a visual assessment performed with unaided eyes would probably have resulted in lower values of SE and SP for VE [50]. This study additionally provides new diagnostic findings on NIRT and ACIS, which have not previously been reported in the literature [14, 15, 18-21].

Alternating current impedance spectroscopy showed strong overall accuracy values of $74 \%$ but did not show particularly well diagnostic performance for either the enamel or dentin caries detection. This renders the 
evaluation and assessment of the method from a clinical point of view more difficult. At the overall caries and the enamel threshold LF and ACIS show a similar range of competence, while NIRT shows significantly weaker performance than the other methods and their combinations with VE (Tables 3,4), as well as the lowest accuracy values of only $50.0 \%$. Additionally, NIRT was more sensitive than specific at the overall caries detection threshold, in contrast to the other methods (Table 3). The use of NIRT led to an increased number of false-positive diagnoses (Table 2). These misinterpretations may have been caused by occlusal staining of healthy molars and are described by a previous in vitro study [20]. Regarding the detection of enamel caries, all diagnostic methods revealed insufficient diagnostic performance, which was mainly caused by low values of SE (Table 3). However, as auxiliaries to VE, ACIS and especially LF increase their diagnostic potential to detect enamel lesions. Both methods seem to complement the high sensitivity for enamel lesions of ICDAS. One main result of this study is the high diagnostic performance of all three auxiliary methods for the detection of dentin caries. This fact is very important for everyday clinical practice, as the use of these diagnostic methods can support the clinician to detect lesions in dentin. However, due to the numerous limitations listed here, the test methods cannot be recommended for occlusal caries detection in general. Finally, it is important to emphasize that the present study investigated the performance of different diagnostic methods and their combination with VE in relation to anatomical-based hard tissue structures, and it did not investigate recently suggested thresholds for operative intervention. Relevant thresholds from the clinician point of view are first caries in the middle third of dentin [40], second caries in the outer fifth of dentin [41] or third caries reaching the inner quarter of dentin [42]. Here, as shown in Table 3, the hypothesis can be made that different thresholds are associated with different diagnostic performance data. It must therefore be clearly stated that the shown data should not be transferred unconditionally to other clinical situations and that further research is needed to test the diagnostic accuracy in relation to thresholds for operative interventions.

\section{Conclusions}

All three test methods, NIRT, LF and ACIS, revealed its individual strength and limitations, but none of them exhibited impeccable diagnostic performance and is generally recommendable for occlusal caries detection. Laser fluorescence measurement and ACIS show an increase in diagnostic performance as adjunct methods to visual examination. All methods are helpful diagnostic tests to detect non-cavitated caries in dentin.

\section{Abbreviations}

NIRT: Near-infrared transillumination; LF: Laser fluorescence measurement; ACIS: Alternating current impedance spectroscopy; VE: Visual examination; BWR: Bitewing radiography; SE: Sensitivity; SP: Specificity; ICDAS: International Caries Detection and Assessment System II; AUROC: Receiver operating characteristic curve; AUC: Area under the curve; ASA: American Society of Anaesthesiologists; TP: True positives; FN: False negatives; FP: False positives; TN: True negatives; WHO: World Health Organization; DMFT: Decayed/missing/ filled teeth; DMFS: Decayed/missing/filled surfaces; Cl: Confidence interval.

\section{Acknowledgements}

Not applicable.

\section{Authors' contributions}

FL, JK and KH collected and analysed the patient data. FL, JK and KH performed and interpreted the statistical analysis and prepared the manuscript. The other two authors ( $\mathrm{RH}$ and GS) contributed equally to the supervision of this work and read and approved the final manuscript. All authors (FL, JK, GS, $\mathrm{RH}$ and $\mathrm{KH}$ ) have read and approved the final version of this manuscript.

\section{Funding}

Open Access funding enabled and organized by Projekt DEAL.

\section{Availability of data and materials}

The data sets generated and/or analysed during the current study are not publicly available. They consist of extensive tables, analyses and forms that contain information beyond the facts published in this analysis. Targeted data can be obtained upon request from the first author (FL).

\section{Declarations}

\section{Ethics approval and consent to participate}

The study was approved by the Ethics Committee of the Medical Faculty of the Ludwig-Maximilians University of Munich (Project Number 013-12).Written consent was obtained from all participants.

\section{Consent for publication}

Not applicable.

\section{Competing interest}

The authors declare that they have no competing interests.

Received: 19 June 2020 Accepted: 25 February 2021

Published online: 05 March 2021

\section{References}

1. Kassebaum NJ, Smith AGC, Bernabe E, Fleming TD, Reynolds AE, Vos T, Murray CJL, Marcenes W, Collaborators GBDOH. Global, regional, and national prevalence, incidence, and disability-adjusted life years for oral conditions for 195 countries, 1990-2015: a systematic analysis for the global burden of diseases, injuries, and risk factors. J Dent Res. 2017;96(4):380-7

2. Marthaler TM. Caries status in Europe and predictions of future trends. Caries Res. 1990;24(6):381-96.

3. Braun A, Guiraud LM, Frankenberger R. Histological validation of ICDAS II and radiological assessment of occlusal carious lesions in permanent teeth. Odontology. 2017;105(1):46-53.

4. Pieper K, Lange J, Jablonski-Momeni A, Schulte AG. Caries prevalence in 12-year-old children from Germany: results of the 2009 national survey. Community Dent Health. 2013;30(3):138-42.

5. Schwendicke F, Splieth C, Breschi L, Banerjee A, Fontana M, Paris S, Burrow MF, Crombie F, Page LF, Gaton-Hernandez P, et al. When to intervene in the caries process? An expert Delphi consensus statement. Clin Oral Investig. 2019;23:3691-703. 
6. Marthaler TM. Changes in dental caries 1953-2003. Caries Res. 2004;38(3):173-81.

7. Topping GVA, Pitts NB. Clinical visual caries detection. Monogr Oral Sci. 2009;21:15-41.

8. Baelum V, Hintze H, Wenzel A, Danielsen B, Nyvad B. Implications of caries diagnostic strategies for clinical management decisions. Community Dent Oral Epidemiol. 2012;40(3):257-66.

9. Schwendicke F, Tzschoppe M, Paris S. Radiographic caries detection: a systematic review and meta-analysis. J Dent. 2015;43(8):924-33.

10. Bader JD, Shugars DA. A systematic review of the performance of a laser fluorescence device for detecting caries. J Am Dent Assoc. 2004;135(10):1413-26.

11. Kühnisch J, Berger S, Goddon I, Senkel H, Pitts N, Heinrich-Weltzien R. Occlusal caries detection in permanent molars according to $\mathrm{WHO}$ basic methods, ICDAS II and laser fluorescence measurements. Community Dent Oral Epidemiol. 2008;36(6):475-84.

12. Longbottom C, Huysmans MC, Pitts NB, Los P, Bruce PG. Detection of dental decay and its extent using a.c. impedance spectroscopy. Nat Med. 1996;2(2):235-7.

13. Söchtig F, Hickel R, Kühnisch J. Caries detection and diagnostics with near-infrared light transillumination: clinical experiences. Quintessence Int. 2014;45(6):531-8.

14. Mortensen D, Dannemand K, Twetman S, Keller MK. Detection of non-cavitated occlusal caries with impedance spectroscopy and laser fluorescence: an in vitro study. Open Dent J. 2014;8:28-32.

15. Mortensen D, Hessing-Olsen I, Ekstrand KR, Twetman S. In-vivo performance of impedance spectroscopy, laser fluorescence, and bitewing radiographs for occlusal caries detection. Quintessence Int. 2018;49(4):293-9.

16. Neuhaus KW, Ellwood R, Lussi A, Pitts NB. Traditional lesion detection aids. Monogr Oral Sci. 2009;21:42-51.

17. Neuhaus KW, Longbottom C, Ellwood R, Lussi A. Novel lesion detection aids. Monogr Oral Sci. 2009;21:52-62.

18. Bussaneli DG, Restrepo M, Boldieri T, Pretel H, Mancini MW, SantosPinto L, Cordeiro RC. Assessment of a new infrared laser transillumination technology $(808 \mathrm{~nm})$ for the detection of occlusal caries-an in vitro study. Lasers Med Sci. 2015;30(7):1873-9.

19. Schaefer G, Pitchika V, Litzenburger F, Hickel R, Kühnisch J. Evaluation of occlusal caries detection and assessment by visual inspection, digital bitewing radiography and near-infrared light transillumination. Clin Oral Investig. 2018;22:2431-8.

20. Litzenburger F, Lederer A, Kollmuss M, Hickel R, Kunzelmann KH, Heck K. Near-infrared transillumination with high dynamic range imaging for occlusal caries detection in vitro. Lasers Med Sci. 2020;35:2049-58.

21. Tassoker M, Sener S, Karabekiroglu S. Occlusal caries detection and diagnosis using visual ICDAS criteria, laser fluorescence measurements and near-infrared light transillumination images. Med Princ Pract. 2019;29:25-31.

22. Singh R, Tandon S, Rathore M, Tewari N, Singh N, Shitoot AP. Clinical performance of ICDAS II, radiovisiography, and alternating current impedance spectroscopy device for the detection and assessment of occlusal caries in primary molars. J Indian Soc Pedod Prev Dent. 2016:34(2):152-8.

23. Bujang MA, Adnan TH. Requirements for minimum sample size for sensitivity and specificity analysis. J Clin Diagn Res. 2016;10(10):YE01-6.

24. Kühnisch J. Near-infrared light transillumination. In: Ferreira Zandona A, Longbottom C, editors. Detection and assessment of dental caries: a clinical guide. Cham: Springer; 2019. p. 151-8.

25. Tassery H, Levallois B, Terrer E, Manton DJ, Otsuki M, Koubi S, Gugnani $\mathrm{N}$, Panayotov I, Jacquot B, Cuisinier $\mathrm{F}$, et al. Use of new minimum intervention dentistry technologies in caries management. Aust Dent J. 2013;58(Suppl 1):40-59.

26. Chen Z, Lu ZM, Falk S, Nicola PTI, Jo EF. Managing carious lesions: consensus recommendations on carious tissue removal. Zhonghua Kou Qiang Yi Xue Za Zhi. 2016;51(12):712-6.

27. R Core Team. R: a language and environment for statistical computing. Vienna, Austria: R Foundation for Statistical Computing; 2019.

28. Matthews DE, Farewekk VT. Using and understanding medical statistics. 5th, revised and extended ed. Oxford: Karger; 2015.

29. Goksuluk D, Korkmaz S, Zararsiz G, Karaağaoğlu AE. easyROC: an interactive web-tool for ROC curve analysis using $\mathrm{R}$ language environment. R J. 2016;8(2):213-30
30. Hosmer DW, Lemeshow S. Applied logistic regression. 2nd ed. New York: Wiley; 2000. p. 156-64.

31. Fleiss JL, Cohen J. The equivalence of weighted kappa and the intraclass correlation coefficient as measures af reliability. Educ Psychol Meas. 1973;33:613-9.

32. Landis JR, Koch GG. The measurement of observer agreement for categorical data. Biometrics. 1977;33(1):159-74.

33. Cohen J. Weighted kappa: Nominal scale agreement provision for scaled disagreement or partial credit. Psychol Bull. 1968;70(4):213.

34. Jordan RA, Bodechtel C, Hertrampf K, Hoffmann T, Kocher T, Nitschke I, Schiffner U, Stark H, Zimmer S, Micheelis W, et al. The Fifth German Oral Health Study (Funfte Deutsche Mundgesundheitsstudie, DMS V) rationale, design, and methods. BMC Oral Health. 2014;14:161.

35. Demirci M, Tuncer S, Yuceokur AA. Prevalence of caries on individual tooth surfaces and its distribution by age and gender in university clinic patients. Eur J Dent. 2010;4(3):270-9.

36. Weerheijm KL, Gruythuysen RJ, van Amerongen WE. Prevalence of hidden caries. ASDC J Dent Child. 1992;59(6):408-12.

37. Jablonski-Momeni A, Winter J, Petrakakis P, Schmidt-Schafer S. Caries prevalence (ICDAS) in 12-year-olds from low caries prevalence areas and association with independent variables. Int J Paediatr Dent. 2014;24(2):90-7.

38. Lussi A. Comparison of different methods for the diagnosis of fissure caries without cavitation. Caries Res. 1993;27(5):409-16.

39. Ricketts D, Kidd E, Weerheijm K, de Soet H. Hidden caries: what is it? Does it exist? Does it matter? Int Dent J. 1997;47(5):259-65.

40. Ekstrand KR, Ricketts DN, Kidd EA. Reproducibility and accuracy of three methods for assessment of demineralization depth of the occlusal surface: an in vitro examination. Caries Res. 1997;31(3):224-31.

41. Kühnisch J. Discussion on the paper: "When to intervene in the caries process? An expert Delphi consensus statement." Clin Oral Investig. 2020;24(5):1865-7.

42. European Society of Endodontology developed b, Duncan HF, Galler KM, Tomson PL, Simon S, El-Karim I, Kundzina R, Krastl G, Dammaschke $\mathrm{T}$, Fransson $\mathrm{H}$, et al. European Society of Endodontology position statement: management of deep caries and the exposed pulp. Int Endod J. 2019;52(7):923-34.

43. Baelum V. What is an appropriate caries diagnosis? Acta Odontol Scand. 2010;68(2):65-79.

44. Gomez J. Detection and diagnosis of the early caries lesion. BMC Oral Health. 2015;15(Suppl 1):S3.

45. Gomez J, Zakian C, Salsone S, Pinto SC, Taylor A, Pretty IA, Ellwood R. In vitro performance of different methods in detecting occlusal caries lesions. J Dent. 2013;41(2):180-6.

46. Rodrigues JA, Hug I, Diniz MB, Lussi A. Performance of fluorescence methods, radiographic examination and ICDAS II on occlusal surfaces in vitro. Caries Res. 2008:42(4):297-304.

47. Costa AM, Paula LM, Bezerra AC. Use of Diagnodent for diagnosis of non-cavitated occlusal dentin caries. J Appl Oral Sci. 2008;16(1):18-23.

48. Astvaldsdottir A, Holbrook WP, Tranaeus S. Consistency of DIAGNOdent instruments for clinical assessment of fissure caries. Acta Odontol Scand. 2004;62(4):193-8.

49. Gimenez T, Piovesan C, Braga MM, Raggio DP, Deery C, Ricketts DN, Ekstrand KR, Mendes FM. Visual inspection for caries detection: a systematic review and meta-analysis. J Dent Res. 2015;94(7):895-904.

50. Neuhaus KW, Jost F, Perrin P, Lussi A. Impact of different magnification levels on visual caries detection with ICDAS. J Dent. 2015;43(12):1559-64

51. Pitts NB, Ekstrand KR, Foundation I. International caries detection and assessment system (ICDAS) and its international caries classification and management system (ICCMS) - methods for staging of the caries process and enabling dentists to manage caries. Community Dent Oral Epidemiol. 2013;41(1):e41-52.

\section{Publisher's note}

Springer Nature remains neutral with regard to jurisdictional claims in published maps and institutional affiliations. 